Mothers' perceptions on and learning from infant and young child-feeding videos displayed in Mother and Child Health Centers in Kenya : a qualitative and quantitative approach

Schneider, Lauriina

2021-08

Schneider , L , Kosola , M , Uusimäki , K, Ollila , S , Lubeka , C , Kimiywe , J \& Mutanen , M 2021 , ' Mothers' perceptions on and learning from infant and young child-feeding videos displayed in Mother and Child Health Centers in Kenya : a qualitative and quantitative approach ' , Public Health Nutrition , vol. 24 , no. 12 , 1368980021002342 , pp. 3845-3858 . https://doi.org/10.1017/S

http://hdl.handle.net/10138/339838

https://doi.org/10.1017/S1368980021002342

cc_by

publishedVersion

Downloaded from Helda, University of Helsinki institutional repository.

This is an electronic reprint of the original article.

This reprint may differ from the original in pagination and typographic detail.

Please cite the original version. 


\title{
Mothers' perceptions on and learning from infant and young child-feeding videos displayed in Mother and Child Health Centers in Kenya: a qualitative and quantitative approach
}

\author{
Lauriina Schneider ${ }^{1, *}$ (1), Mikko Kosola ${ }^{1}$, Kerttu Uusimäki ${ }^{1}$, Sari Ollila ${ }^{1}$, Crippina Lubeka $^{2}$, \\ Judith Kimiywe ${ }^{2}$ and Marja Mutanen ${ }^{1}$ \\ 'Department of Food and Nutrition, Faculty of Agriculture and Forestry, University of Helsinki, P.O. Box 66, 00014 \\ Helsinki, Finland: ${ }^{2}$ Department of Food, Nutrition and Dietetics, School of Applied Human Sciences, Kenyatta \\ University, Nairobi, Kenya
}

Submitted 12 November 2020: Final revision received 16 February 2021: Accepted 19 May 2021: First published online 26 May 2021

\begin{abstract}
Objective: The objective was to explore mothers' perceptions on educational videos on infant and young child-feeding practices, and to assess whether viewing frequencies would influence maternal knowledge, attitudes and feeding practices (KAP).

Design: A set of forty-seven videos were displayed in health centres for 6 months. At 3 months, we conducted focus group discussions (FGD) with mothers and, at 6 months, administered KAP-questionnaire-based interviews to mothers. Using a quasi-experimental design, we compared groups according to video viewing frequencies.

Setting: The study was conducted in a slum in Nairobi and a rural area in Machakos, Kenya. We installed TV screens in waiting rooms of six Mother and Child Health Centers, where mothers could choose to watch them.

Participants: Forty-three mothers with children aged 0-48 months participated in six FGD and 547 mothers of children aged 0-23 months in KAP interviews.

Results: The mothers from the FGD found the videos acceptable and beneficial. Videos enhanced mothers' learning and empowered them to support others in learning. The KAP data showed that after adjustments, breast-feeding $(P=0.06)$, complementary feeding knowledge $(P=0 \cdot 01)$, complementary feeding attitudes $(P=0.08)$ and hygiene knowledge and practices $(P=0.003)$ were better among mothers who had seen videos three to four times, or five or more times, compared with mothers who had seen the videos once or twice.

Conclusions: Videos were an accepted form of education and were beneficial when watched repeatedly. The videos could be a good addition to current infant and young child-feeding education efforts in Kenya.
\end{abstract}

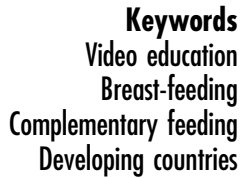

deo education Breast-feeding Developing countries
Barriers to proper child-feeding practices in African countries include limited or inaccurate breast-feeding and complementary feeding knowledge $\mathrm{e}^{(1,2)}$. Currently, childfeeding knowledge and attitudes are often obtained through social learning, that is, from a young age observing others taking care of their children in local surroundings ${ }^{(3,4)}$. Thereby, child-feeding models are passed on from generation to generation, forming parameters within which mothers feel they can make child-feeding decisions ${ }^{(3)}$. Social learning is a strong determinant of how a young woman will care for her own children ${ }^{(3)}$. Culturally acquired feeding behaviours are difficult to change; often, these do not conform to current recommendations ${ }^{(1,5,6)}$.

It is important to find methods to influence cultural feeding models in ways that motivate change. Modern technology offers opportunities to educate with methods that imitate social learning. Caregivers can be exposed to correct infant and young child-feeding (IYCF) models on video. Video cost-effectively educates multiple persons at a time, while allowing them to observe the actions of 
others, as they would in their everyday life ${ }^{(7)}$. Furthermore, video-based education provides a standardised opportunity to learn, despite differences in literacy or other learning skills $^{(8)}$. Moreover, video can both convey skills that are hard to explain verbally ${ }^{(9)}$ and allow an individual to learn inductively $^{(9)}$. Additionally, the same message can be repeated by showing the video multiple times, promoting learning by repetition ${ }^{(4)}$. Educating groups instead of individuals may increase the acceptability of new practices, as peer support seems to promote a change in attitudes ${ }^{(10,11)}$.

In their review, Tuong et al. ${ }^{(8)}$ found that video interventions appear effective in modifying health behaviours. Scheinmann et al. ${ }^{(12)}$ illustrated improved maternal knowledge among immigrant women in the USA, following exposure to an educational video portraying proper feeding practices. In India, compared with traditional counselling, video education on breast-feeding was associated with increased knowledge and improved exclusive breastfeeding rates was noticed 3 and 4 months after watching the videos ${ }^{(13)}$. In Africa, the use of video has been limitedly studied and the focus of video education has been on neonatal and infant health and breast-feeding ${ }^{(14-16)}$.

Despite the possible benefits of using video in education, such benefits will not be actualised unless the target audience finds the videos acceptable and useful. Thus, our first aim was to qualitatively explore mothers' perceptions of educational IYCF videos when distributed through Maternal and Child Health Centers (MCHC) in Kenya. The second aim was to quantitatively assess whether viewing frequencies would influence maternal knowledge, attitudes and IYCF practices.

\section{Methods}

\section{Study area}

The study was carried out in Ruraka sub-county in Nairobi and the Masinga sub-county in Machakos, Kenya. Ruraka is a densely populated urban slum, whereas Masinga is a more sparsely populated rural area. These two areas were selected, as both rate poorly on nutrition indicators ${ }^{(17)}$. Area health officers selected six MCHC: three in Nairobi (MCHC 1-3) and three in Machakos (MCHC 4-6). The selection used convenience sampling, selecting centres with variations in socioeconomic status and geographic location. All centres were public and government-run. Children have appointments at the MCHC monthly until they turn 16 months, after which they go in once a year until 5 years of age.

\section{Study phases}

We conducted focus group discussions (FGD) and a quasiexperimental intervention ${ }^{(18)}$ where we compared three groups of mother-child pairs, according to how often they had seen videos. Prior to the study, we underwent a 2 -yearlong process of video production, as Supplemental Figure 1 describes in detail. The videos were based on WHO and
UNICEF guidelines ${ }^{(19-22)}$ and discussions with local experts and mothers. The topics for educational videos address problematic areas in breast-feeding, complementary feeding, hygiene and basic childcare in the African setting (Supplemental Table 1) and the production thereof was based on previous research ${ }^{(23)}$.

We organised the installation of television screens in the waiting rooms of the selected MCHC in March-April of 2016. We asked for the full set of videos to be played twice each morning, the set playing for approximately $2 \mathrm{~h}$, during a period of 6 months. In addition, the healthcare workers wanted to use the videos during their health talks, although we did not require this. These health talks, which occur daily in some MCHC and weekly or less often in other $\mathrm{MCHC}$, are customary in Kenya. During these talks, healthcare personnel educate mothers in waiting rooms on a select topic. We avoided giving strict rules for video usage so that the results would be representative of how the videos work if scaled up.

Three months after the installation of the TV and videos, we conducted FGD to understand how the mothers visiting MCHC perceived the videos. After another 3 months, we administered knowledge, attitude and practice (KAP) questionnaire-based interviews to mothers to see if watching the videos repeatedly would impact their learning.

Two field coordinators, one in each geographic area, made monthly control visits to the centres, checked that the videos were played each day, asked what videos had been used for health talks and assisted with any arising problems. In two of the centres, the waiting rooms in which the TV sets were installed were renovated, resulting in breaks in video showings lasting up to 3 weeks. In one centre, the health workers were initially unwilling to participate and the videos were shown inconsistently at the beginning of the study.

\section{Focus group discussions}

In June and July 2016, we conducted six FGD: one in each MCHC, three in Nairobi and three in Machakos. The participants were selected by purposeful sampling from mothers then present at the MCHC by the field coordinators. Mothers who had children under the age of 5 years and who had reported seeing some of the videos at least once were considered eligible. Between five and twelve mothers participated in each discussion, in total forty-three mothers. Participation was voluntary, and the mothers were not compensated for their time. The FGD were conducted in local languages by a nutritionist from Nairobi (moderator), accompanied by a local nutritionist, while one of the researchers (K.U.) observed and took notes. The moderator and local nutritionist were experienced with conducting FGD and also received training by one of the researchers (J.K.). Prior to the discussions, the moderator explained the purpose of the study to the participants, who filled in informed consent forms. The discussions lasted approximately $30 \mathrm{~min}$ and were audio-recorded. A discussion 
guide that had been compiled prior to the FGD was used. The main topics discussed were the mothers' overall feelings towards the videos, mothers' opinions on the content of the videos, things the mothers had not understood and whether the mothers had found the videos helpful. Individual videos were not discussed unless the mothers brought up a specific video.

\section{Knowledge, attitude and practice interviews}

In the same six MCHC as the earlier FGD, twelve Kenyan nutritionists and nutrition students administered questionnaire-based interviews to mothers 6 months after the start of the study, that is, September and October 2016. The interviewers were trained to use a mobile phonebased questionnaire by the technical developer thereof, and the interviews lasted approximately 30-40 min. Prior to an interview, the interviewer explained the purpose of the study to the participant, who agreed to participate. We used a KAP survey form ${ }^{(24)}$ frequently used in Kenya, which we modified by excluding unrelated questions and adding a few video-specific questions. The final questionnaire included questions on socio-demographic characteristics, twenty-three questions on breast-feeding, nineteen on complementary feeding (including a $24 \mathrm{~h}$ dietary recall), fifteen on general nutrition knowledge and fourteen on hygiene. The mothers were also asked how many times they had watched videos, either just one video or anywhere up to the full set. The questionnaire was structured with multiple choices and the possibility to add own comments.

Purposeful sampling was used to recruit mother-child pairs in equal numbers from groups formed according to a child's age: 0-5 months, 6-8 months, 9-11 months and 12-23 months. Recruitment resulted in twenty-five mother-child pairs in each group, altogether 100 from each MCHC. We aimed for 100 mother-child pairs per MCHC as it was possible to get this many mothers in each of the $\mathrm{MCHC}$ in one day, while allowing us a large enough sample for analyses even when divided into three groups according to video viewing frequencies. Grouping selection concerned the difference in the WHO recommendations for IYCF for the above age groups ${ }^{(18)}$. All mother-child pairs visiting the MCHC on the day of the interviews were included until the desired number of interviews had been conducted. The inclusion criteria were that the caretaker was the mother of the child and that the child was 0-23 months old. Additionally, the mother was required to have seen a portion of the videos at least once. The inclusion criteria were not strictly followed. Consequently, we excluded thirty-nine mothers: thirty-five reported having never seen the videos, three caretakers answered not knowing if the child was currently breastfed and one caretaker was over 60 years old, thus ruling out possible motherhood. Fortythree mothers refused to participate, with the most common reason being lack of time. Therefore, the final number of subjects was 547 mother-child pairs.

\section{Analyses}

Analysis of the focus group discussion data

Our inductive analysis of the FGD followed the principles of content analysis ${ }^{(25)}$. Three authors (L.S., K.U. and S.O.) read the transcribed and translated data multiple times to achieve familiarity. Statements and sentences with similar meanings were identified and labelled with codes. Organising data under the codes continued until consensus on the meanings of the data was reached. Thereafter, code sorting used fifteen subcategories. The subcategories were further grouped under initial categories; subsequently, these subcategories were further categorised under main themes that described the broader phenomena emerging from the analyses ${ }^{(26)}$. Discussions between the researchers led to decisions on final themes, categories and subcategories.

\section{Analyses of the knowledge, attitudes and feeding practice data}

To condense the information in the separate variables, questions were grouped into indexes: eight knowledge questions on breast-feeding and five on complementary feeding, six attitude questions on breast-feeding and six on complementary feeding, and five practice questions on breast-feeding. Knowledge and practice questions for hygiene were few (five), and these were grouped together into one index. Included in the indexes were all questions for which the answer possibilities could be valued as either correct or incorrect. The indexes were created by giving values of 1 for all correct answer possibilities within a question and a value of 0 for all incorrect answer possibilities. The subsequent scaling of indexes ensured the maximum value of each index was 100. The dietary diversity score (DDS) and meal frequency from the previous $24 \mathrm{~h}$ were used as indicators of complementary feeding practices.

To study associations between the frequency of the video viewings and other studied variables, the interviewed mother-child pairs were divided into three roughly equally sized groups: those who had seen any of the videos one or two times ( $n$ 199), three or four times ( $n$ 154) and five or more times ( $n$ 194).

Differences between categorical variables were tested with either the $\chi^{2}$ test or Fisher's exact test. For continuous variables, differences between groups were tested with ANOVA or, if the normality assumption was not met, with the Kruskal-Wallis test. Normality was assessed visually from Q-Q plots. Where ANOVA was used, post hoc pairwise comparisons were performed with Tukey's test. If a potential confounder was associated with an independent variable (indexes, DDS and meal frequency) and a dependent variable (the number of times videos had been watched), it was included in the analyses. Health centre, tribe, child's age, mother's age, number of children in household and education were recognised as potential confounding factors. Statistical significance was determined as $P<0.05$, which was also used as a cut-off value for confounding factors. All analyses were done using SAS 9.4 ${ }^{(27)}$. 
Table 1 Socio-demographic characteristics of the study population from the focus group discussions

\begin{tabular}{|c|c|c|c|c|c|c|c|c|c|c|c|c|}
\hline \multirow{3}{*}{$\begin{array}{l} \\
n \\
\text { Age (years) }\end{array}$} & \multicolumn{2}{|c|}{$\mathrm{MCHC}^{*} 1$} & \multicolumn{2}{|c|}{$\mathrm{MCHC}^{*} 2$} & \multicolumn{2}{|c|}{$\mathrm{MCHC}^{*} 3$} & \multicolumn{2}{|c|}{$\mathrm{MCHC}^{*} 4$} & \multicolumn{2}{|c|}{$\mathrm{MCHC}^{*} 5$} & \multicolumn{2}{|c|}{$\mathrm{MCHC} * 6$} \\
\hline & 7 & & 12 & & 5 & & 7 & & 6 & & 6 & \\
\hline & & & & & & & & & & & & \\
\hline Mean and range & $26 \cdot 0$ & $20-31$ & $26 \cdot 8$ & $21-30$ & 33.0 & $28-39$ & $25 \cdot 6$ & $21-38$ & $27 \cdot 8$ & $23-33$ & 29.5 & $19-38$ \\
\hline \multicolumn{13}{|l|}{ Education (\%) } \\
\hline Primary school & $42 \cdot 9$ & & $8 \cdot 3$ & & $40 \cdot 0$ & & $28 \cdot 6$ & & $33 \cdot 3$ & & $50 \cdot 0$ & \\
\hline Secondary school & $57 \cdot 1$ & & 33.3 & & $20 \cdot 0$ & & 71.4 & & $16 \cdot 7$ & & 0 & \\
\hline College & 0 & & $41 \cdot 7$ & & $40 \cdot 0$ & & 0 & & $50 \cdot 0$ & & $16 \cdot 7$ & \\
\hline NAt & 0 & & $16 \cdot 7$ & & 0 & & 0 & & 0 & & $33 \cdot 3$ & \\
\hline \multicolumn{13}{|l|}{ Occupation (\%) } \\
\hline Housewife & $85 \cdot 7$ & & $16 \cdot 7$ & & $60 \cdot 0$ & & $85 \cdot 7$ & & $16 \cdot 7$ & & $50 \cdot 0$ & \\
\hline Employed & $14 \cdot 3$ & & $75 \cdot 0$ & & $40 \cdot 0$ & & $14 \cdot 3$ & & $83 \cdot 3$ & & $50 \cdot 0$ & \\
\hline NAt & 0 & & $8 \cdot 3$ & & 0 & & 0 & & 0 & & 0 & \\
\hline \multicolumn{13}{|l|}{ Marital status (\%) } \\
\hline Married & $85 \cdot 7$ & & $58 \cdot 3$ & & $80 \cdot 0$ & & $85 \cdot 7$ & & $16 \cdot 7$ & & $83 \cdot 3$ & \\
\hline Single & $14 \cdot 3$ & & $25 \cdot 0$ & & $20 \cdot 0$ & & $14 \cdot 3$ & & $83 \cdot 3$ & & $16 \cdot 7$ & \\
\hline NAt & 0 & & $16 \cdot 7$ & & 0 & & 0 & & 0 & & 0 & \\
\hline \multicolumn{13}{|l|}{ Number of children } \\
\hline Mean and range & 1.6 & $1-3$ & $N A^{*}$ & & $2 \cdot 4$ & $1-4$ & 2.6 & $1-7$ & 1.8 & $1-4$ & 3.3 & $1-8$ \\
\hline Age of youngest child (months) & & & & & & & & & & & & \\
\hline mean and range & $17 \cdot 8$ & $6-48$ & $8 \cdot 8$ & $4-18$ & 17.4 & $2-48$ & $5 \cdot 4$ & $0-15$ & $18 \cdot 0$ & $0-36$ & $18 \cdot 7$ & $0-24$ \\
\hline
\end{tabular}

${ }^{*} \mathrm{MCHC}$, Mother and Child Health Center.

†Did not answer the question.

\section{Results}

\section{Focus group discussions}

Participant characteristics from the focus group discussions

Table 1 describes the socio-demographic characteristics of the mothers who participated in the FGD. The mothers were on average 28 years old and had on average two children. Most mothers were married, with the exception of eight who were single and two who chose not to give their marital status. Of the forty-three mothers, thirteen had gone to primary school, fifteen to secondary school and eleven to college; four mothers did not state their education.

\section{Results from the focus group discussion analysis}

The identified three main themes describe different aspects of learning: social learning from videos, assisted learning through health talks and peer support. Figure 1 summarises these together with the barriers to learning as well as the outcomes in behavioural change. These themes, together with demonstrative quotations from the discussions, are presented below.

Social learning from videos

The mothers were eager to learn and felt that they had learned a lot from the videos, ranging from breast-feeding positions to 'what to feed your child', even to 'how to live with your husband'. Some of the common answers included: knowing what foods to give during complementary feeding; understanding exclusive breast-feeding and how to breastfeed in practice; keeping a clean house, hygienic cooking and washing hands; eating well during pregnancy; the importance of delivering at a hospital and attending a clinic and that HIV positive mothers can breastfeed. However, other themes from the video set, such as illnesses and parasites, individual nutrients and vaccinations, were not mentioned at all. The mothers reported having begun to practise what they learned. 'I have learned to take time to breastfeed. Only after the child reached six months I started giving proper food. ' - Mother, MCHC 1

The information from the videos changed old beliefs. 'The videos taught us many things, whereby it has removed us from the life we used to see, the way our grandparents used to do.'-Mother, MCHC 2. Among the most frequently mentioned was the belief that HIV positive mothers should not breastfeed. Moreover, the videos helped the mothers trust in their own judgement, allowing them to follow recommendations even when others questioned them. 'Someone saw me giving only breastmilk and asked me, 'why can't you give him even water?'. The videos have encouraged me to only breastfeed from the first day of birth to six months.' - Mother, MCHC 3

Assisted learning through bealth talks

The mothers found it easier to follow health talks when videos were incorporated and felt they were learning more from the combination of health talk and videos than a traditional health talk. 'Before, we could learn and immediately after, we'd forget. But now, as we watch videos and are taught by the nurse, we continue practicing at bome.' Mother, MCHC 6. The videos also helped mothers feel capable of doing as was taught, for example, reallocating their food budgets to give a more varied diet to their children.

Most of the mothers said that the videos were easy to understand and that the language used was simple. However, according to some, Kiswahili was not understood by all mothers in the rural area. Even so, the visual 


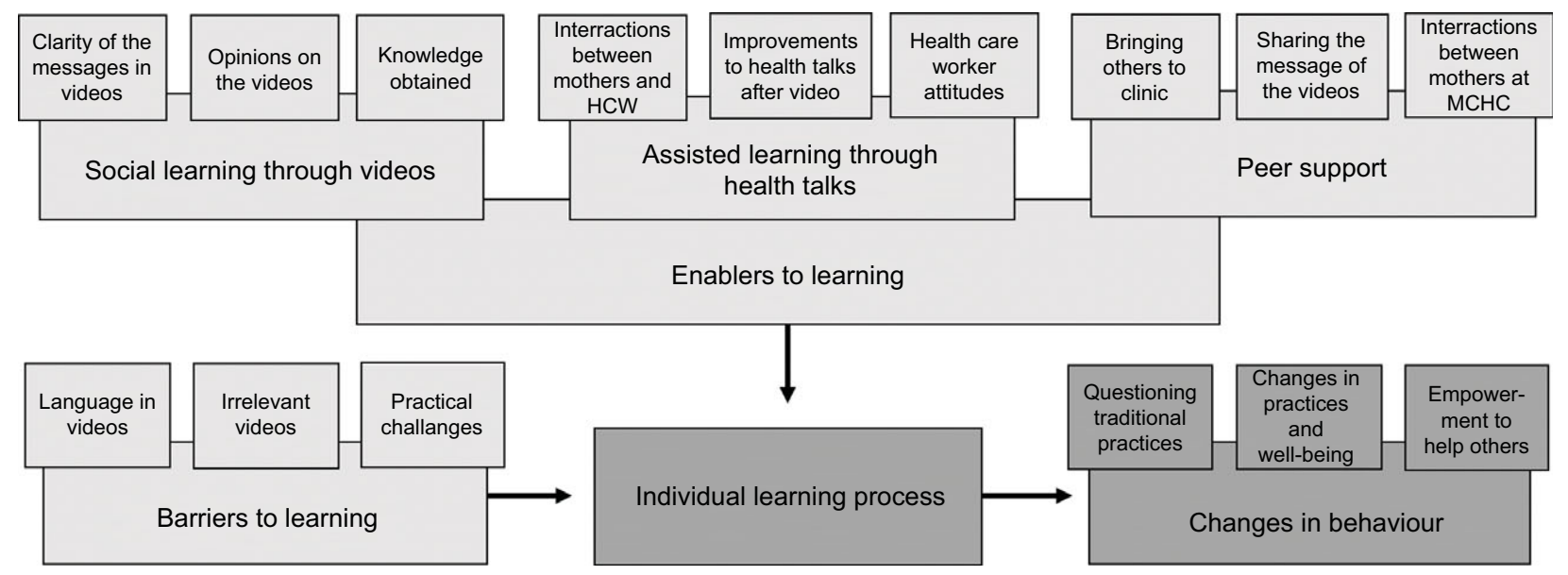

Fig. 1 A conceptual model of the learning process and implications as enabled by the videos

aspect of the videos was considered beneficial. 'You see her say and then she acts.' - Mother, MCHC 4.

The challenges that the mothers experienced were the interruption of a video when called in for an appointment and seeing the same videos at each visit. One mother suggested that mothers should be grouped according to the age of their child and be given health talks and shown videos that applied to their current situation. 'The videos should be changed as we progress.' Mother, MCHC 2.

\section{Peer support}

The knowledge gained from the videos was freely shared with others, and the topics of the videos were discussed with friends, family and neighbours. 'We have young ladies who don't know much about how to take care of children. I use the knowledge acquired bere to enlighten them.' - Mother, MCHC 6. Many mothers also actively encouraged their friends to attend their appointments, so they too could see the videos. 'I have brought five mothers here who were taking their children to the private bealth facility. It is better to queue and get information than it is to enter in without queuing and not getting information. So I have brought them here to get the knowledge so that their children may grow well.' Mother, MCHC 2. One mother suggested increasing the opportunities for more people to see the videos: 'You should add more places so that others, like fathers, can also get this information.' - Mother, MCHC 5.

The mothers felt confident in their own knowledge and thereby empowered to help their friends and neighbours. 'When I bear one telling the other that "you just introduce [food]" I will say no. That is what I have seen here.' Mother MCHC 3. Mothers also helped their peers at the clinic. 'Some come in late, so when they watch the videos, they ask us what is this? We explain to them. We will be their teachers.' - Mother, MCHC 6

\section{Knowledge, attitudes and practices interviews}

Participant characteristics from the knowledge, attitudes and feeding practice interviews

Table 2 describes the socio-demographic characteristics of the mother-child pairs in the KAP interviews. The mothers' average age was 26.2 years, approximately $87 \%$ were married and their average number of children was $2 \cdot 2$. Most of the mothers had either primary or secondary level education. Approximately $62 \%$ of all respondents were housewives, $8.4 \%$ were formally employed and the rest partook in casual labour or were self-employed. There were differences between the groups according to video viewings in the age of the mother, the age of the youngest child, number of children in household and the tribe the mother belonged to.

\section{Mothers' knowledge}

The general knowledge on breast-feeding recommendations was high among the mothers. Almost everyone (97.1\%) knew that babies should be exclusively breastfed and $74.8 \%$ knew that a baby should be put on the breast within an hour from birth (Table 3). However, breastfeeding benefits were not well known; $<40 \%$ of the mothers knew that breast milk protects against infections and that breast-feeding helps baby's to develop. Likewise, most mothers did not know what they should do if there was not enough breast milk, as only $11.5 \%$ would seek for help to improve breast-feeding and $23.4 \%$ would eat or drink more themselves.

The knowledge on complementary feeding was more uniform, as about half of the mothers knew the correct answers to the questions or at least one answer possibility. For example, that thick porridge is preferable and that 9-month-olds should get three to four meals plus snacks every day. However, about a third of the mothers answered not knowing any benefits to feeding children 
Table 2 Socio-demographic characteristics of the study population from the knowledge, attitudes and feeding practices (KAP) interviews

\begin{tabular}{|c|c|c|c|c|c|c|c|c|c|}
\hline \multirow{3}{*}{ Age group (\%) } & \multirow[t]{2}{*}{$n$} & \multirow{2}{*}{$\frac{\text { All mothers* }}{n 547}$} & \multicolumn{2}{|c|}{$\begin{array}{c}\text { Videos seen } \\
1-2 \text { times }\end{array}$} & \multicolumn{2}{|c|}{$\begin{array}{l}\text { Videos seen } \\
3-4 \text { times }\end{array}$} & \multicolumn{2}{|c|}{$\begin{array}{l}\text { Videos seen } 5 \\
\text { or more } \\
\text { timest }\end{array}$} & \multirow[t]{2}{*}{$P$-value } \\
\hline & & & $n 199$ & & $n 154$ & & $n 194$ & & \\
\hline & & & & & & & & & $0.002 \ddagger$ \\
\hline Child $0-5$ months & 162 & $29 \cdot 6$ & $45 \cdot 1$ & & 31.5 & & 23.5 & & \\
\hline Child $6-8$ months & 135 & 24.7 & $34 \cdot 8$ & & $31 \cdot 1$ & & $34 \cdot 1$ & & \\
\hline Child 9-11 months & 119 & $21 \cdot 8$ & $27 \cdot 7$ & & $24 \cdot 4$ & & $47 \cdot 9$ & & \\
\hline Child $12-23$ months & 131 & 23.9 & $35 \cdot 1$ & & 24.4 & & 40.5 & & \\
\hline Age of mother (years) & 547 & $26 \cdot 2$ & $25 \cdot 8$ & $5 \cdot 1$ & 25.4 & 4.7 & $27 \cdot 3$ & 4.9 & $0.003 \S$ \\
\hline Age of youngest child (months) & 547 & $8 . \overline{4}$ & 7.9 & $6 \cdot 1$ & 8.0 & $5 \cdot 4$ & 9.2 & $5 \cdot 1$ & $0.002 \S$ \\
\hline Number of children in household & 547 & $2 \cdot 2$ & $2 \cdot 2$ & $1 \cdot 3$ & $2 \cdot 1$ & $1 \cdot 1$ & $2 \cdot 4$ & $1 \cdot 3$ & $0.046 \S$ \\
\hline Marital status (\%) & & & & & & & & & $0.27 \|$ \\
\hline Married & 473 & $86 \cdot 5$ & $35 \cdot 7$ & & $27 \cdot 7$ & & $36 \cdot 6$ & & \\
\hline Living together & 1 & 0.2 & 0 & & 0 & & 100 & & \\
\hline Divorced & 6 & $1 \cdot 1$ & $66 \cdot 7$ & & $16 \cdot 7$ & & $16 \cdot 7$ & & \\
\hline Widowed & 4 & 0.7 & 0 & & $75 \cdot 0$ & & $25 \cdot 0$ & & \\
\hline Single & 63 & 11.5 & $40 \cdot 3$ & & 30.7 & & $29 \cdot 0$ & & \\
\hline Religion (\%) & & & & & & & & & $0.64 \|$ \\
\hline Christian & 546 & 99.8 & $36 \cdot 5$ & & $28 \cdot 2$ & & 35.4 & & \\
\hline Muslim & 1 & 0.2 & 0 & & 0 & & 100 & & \\
\hline Tribe (\%) & & & & & & & & & $0.003 \ddagger$ \\
\hline Kamba & 309 & $56 \cdot 5$ & $42 \cdot 7$ & & 24.9 & & $32 \cdot 4$ & & \\
\hline Kikuyu & 35 & 6.4 & $25 \cdot 7$ & & $40 \cdot 0$ & & $34 \cdot 3$ & & \\
\hline Luo & 110 & $20 \cdot 1$ & $22 \cdot 7$ & & $30 \cdot 0$ & & $47 \cdot 3$ & & \\
\hline Luhya & 59 & $10 \cdot 8$ & 30.5 & & $39 \cdot 0$ & & 30.5 & & \\
\hline Other & 34 & $6 \cdot 2$ & $44 \cdot 1$ & & 20.6 & & $35 \cdot 3$ & & \\
\hline Level of mother's education (\%) & & & & & & & & & $0.69 \ddagger$ \\
\hline Less than primary & 38 & $6 \cdot 9$ & $35 \cdot 1$ & & 21.6 & & 43.2 & & \\
\hline Primary school & 264 & $48 \cdot 3$ & $39 \cdot 2$ & & 28.9 & & 31.9 & & \\
\hline High school & 171 & $31 \cdot 3$ & $32 \cdot 9$ & & $29 \cdot 4$ & & 37.7 & & \\
\hline College & 74 & $13 \cdot 5$ & $35 \cdot 6$ & & $26 \cdot 0$ & & 38.4 & & \\
\hline Mother's occupation (\%) & & & & & & & & & $0.42 \|$ \\
\hline Employed & 46 & 8.4 & 35.6 & & 33.3 & & $31 \cdot 1$ & & \\
\hline Self employed & 106 & $19 \cdot 4$ & $28 \cdot 3$ & & $31 \cdot 1$ & & $40 \cdot 6$ & & \\
\hline Casual labour & 56 & $10 \cdot 2$ & $32 \cdot 1$ & & 30.4 & & 37.5 & & \\
\hline House wife/not employed & 339 & $62 \cdot 0$ & $39 \cdot 8$ & & $26 \cdot 3$ & & 33.9 & & \\
\hline
\end{tabular}

*Percentage of all respondents in the KAP interviews.

†Percentage of respondents between the three groups.

†Chi-squared.

§Kruskal-Wallis.

IIFisher's exact test.

animal products. About half of the mothers were concerned about stunting.

Regarding hygiene, $70 \%$ of mothers knew that washing hands prevents microbes from entering into the body. However, only a fifth of the mothers knew that good hygiene prevents microbes from getting into food, another fifth knew that handwashing is needed to stay healthy and slightly more mothers knew good hygiene prevents diarrhoea (Table 3).

Table 4 presents the association between the viewing frequencies and the scores from the indexes and complementary feeding indicators. The breast-feeding knowledge index score was significantly better among those who had seen the videos five or more times (mean score 25.5) than those who had seen the videos once or twice (mean score $21 \cdot 8, P=0.001)$. After adjusting for MCHC, tribe and mother's age, the $P$-value (0.06) for the differences between the groups still showed a trend for breast-feeding knowledge. For the complementary feeding knowledge index, the mean score of those who had seen the videos once or twice
(26-1) differed significantly from those who had seen the videos three or four times (mean score $31.4, P=0.001$ ) and those who had seen the videos five or more times (29.6, $P=0 \cdot 02$ ). After adjusting for MCHC, tribe and child's age, the difference remained significant (0.01) (Table 4).

\section{Mothers' attitudes}

Mothers' attitudes were negative towards early skin-to-skin contact, as only $26.5 \%$ answered that a baby should be put to the breast immediately after birth and $28.6 \%$ would feel happy or very happy if that happened to them (Table 3 ). However, almost all would give colostrum to their babies. Although $85.9 \%$ of the mothers felt that breast milk is enough to nourish a baby up to 6 months, only about half of the mothers found no exceptions to the need to exclusively breastfeed.

The attitudes showed that $87.6 \%$ of the mothers felt complementary feeding should begin at 6 months. The majority of mothers would give fruit, vegetables and pulses to 6-month-olds, but only a fourth of mothers would give 
Table 3 Knowledge, attitude and practice (KAP) questions from the KAP interviews. For clarity, only the answer options with an answer frequency of over $5 \%$ are presented here

\begin{tabular}{lcccc}
\hline Knowledge & $\begin{array}{c}\% \text { of mothers } \\
(n 547)\end{array}$ & Attitude & $\begin{array}{c}\% \text { of mothers } \\
(n 547)\end{array}$ & $\begin{array}{c}\% \text { of mothers } \\
(n 547)\end{array}$ \\
\hline
\end{tabular}

\section{Breast-feeding}

For how long in months should a child be fed on breast milk without being given anything other, not even water?

6 months

$97 \cdot 1$

How long after birth does a baby need to be put on the breast?

Less than $1 \mathrm{~h}$

$1-3 \mathrm{~h} \quad 11.9$

Do not know
Should a newborn baby be put directly on their mother's breast immediately after birth?

$\begin{array}{ll}\text { Yes } & 26 \cdot 5 \\ \text { No } & 58 \cdot 9 \\ \text { Do not know } & 14 \cdot 6\end{array}$

How would you feel if your baby was put directly on your breast after birth?

Very unhappy

$16 \cdot 1$

Unhappy

No opinion

34.6

Happy

$20 \cdot 8$

Very happy

$7 \cdot 0$

Why is skin-to-skin contact important for newborn In your opinion, should a baby be given the babies?

Keeps baby warm

\begin{tabular}{ll} 
Bonding & 22.9 \\
\hline
\end{tabular}

Do not know 39.5

What are the benefits of feeding a baby colostrum?

Nutritious to baby

Prevents diseases/infections

34.9

Do not know

Is there any difference between mother's milk and cows' milk?

Proteins different

Breast milk protects against dis-

ease/infection

Breast milk helps baby's intes-

tines develop

Breast-feeding is good for baby's $\quad 30.4$ development

Safety*

Nutrient composition differs ${ }^{*} \quad 13.7$

Do not Know

If you felt that there was not enough breast milk, what would you do?

Give baby formula/other milk

Eat and/or drink more herself

Give porridge or other liquid food

Get help from someone to

improve breast-feeding

Nothing

$9 \cdot 7$

Seek medical attention*

\section{very first milk from the breast at birth?}

Yes

$95 \cdot 1$

Would you feed your baby colostrum?

Yes

$97 \cdot 4$

In your opinion, is breast milk enough to nourish a baby for the first 6 months?

Yes
No

85.9

No

13.5
Even if babies should be exclusively breastfed

for 6 months, are there any exceptions?

Baby is hungry/breast milk is $\quad 36 \cdot 8$

not enough

No such situation $\quad 46.6$

Mothers health problems ${ }^{*} \quad 9.5$

Mother is away and cannot bf $\quad 7.1$

How should a HIV- baby be fed for the first 6 months if the mother is HIV+?

Exclusively breastfeed

Give baby only formula/other milk

Do not know

What and how should a baby under 6 months be fed if you are away?

Breast milk with bottle

Breast milk with cup

Formula or other milk with bottle

Was [NAME] ever breastfed?

Yes

100

Was [NAME] fed colostrum?

Yes

$97 \cdot 3$

Is [NAME] still breast-feeding?

0-5 months - yes $\quad 99.4$

6-8 months - yes $\quad 98.5$

9-11 months - yes $\quad 95.0$

12-23 months - yes $\quad 79.4$

How long after birth

was [NAME] put

to the breast?

$<1 \mathrm{~h}$

$56 \cdot 1$

$1-3 \mathrm{~h}$

28.3

$1-3 d$

$12 \cdot 6$

During the $3 \mathrm{~d}$ after birth was [NAME] given anything other than breast milk?

No

$89 \cdot 2$

9.5 
Table 3 Continued

\begin{tabular}{lcccc}
\hline Knowledge & $\begin{array}{c}\text { \% of mothers } \\
(n 547)\end{array}$ & Attitude & $\begin{array}{c}\text { \% of mothers } \\
(n 547)\end{array}$ & Practice \\
\hline Formula or other milk with cup & 8.4 & & & $\begin{array}{c}\% \text { of mothers } \\
(n 547)\end{array}$ \\
Porridge with bottle/cup & 8.0 & & & \\
Do not know & 9.3 & & &
\end{tabular}

\section{Complementary feeding}

What type of porridge is better for babies, liquid or thick?

Liquid
Thick

(2)

$43 \cdot 0$
$57 \cdot 0$
In your opinion, at what age in months should one introduce first solid/semi-solid foods?
6 months
Other
87.6
$12 \cdot 4$

DDS†
How often should a baby be given food (meals and snacks) after 9 months?
2-3 meals + snacks
3-4 meals + snacks
More often

Do not know

28.9
$49 \cdot 5$
$12 \cdot 1$
9.5

Would you give a 6-month-old baby the following

$\begin{array}{ll}\text { Meat } & 24 \cdot 7 \\ \text { Fish } & 52 \cdot 8 \\ \text { Eggs } & 43 \cdot 3 \\ \text { Fruit } & 96 \cdot 9 \\ \text { Vegetables } & 84 \cdot 1 \\ \text { Pulses } & 74 \cdot 4 \\ \text { Porridge } & 11 \cdot 2\end{array}$

How much food does a baby need at each meal at 9 months?

$1 / 2$ cup/one handful

\section{7}

$17 \cdot 7$

18.5

1 cup or more

Do not know

Should children get the following on a daily basis?

Milk products

Meat

Fish

Eggs

Fruit

Vegetables

Pulses

$75 \cdot 0$
$18 \cdot 8$
$36 \cdot 2$
$29 \cdot 4$
$94 \cdot 5$
80.4
$48 \cdot 5$

In your opinion, is it important to continue breast-feeding when a child has started eating other foods?

What are the benefits of feeding the baby animal products, such as meat, fish and eggs, after 6 months?

Protein/Good quality protein

24.7

47.0

Helps baby grow/develop

29.8

Do not know

Yes, it gives baby nutrier

Yes, it helps baby develop $\quad 36.8$

Yes, it protects baby against $\quad 26.5$

disease

Does it matter if a child is short for his/her age?

$\begin{array}{lr}\text { No } & 42.2 \\ \text { Yes } & 50.5 \\ \text { Do not know } & 7.3\end{array}$

Do not know

11.5

Do not know

Do you feel that a child's diet affects his/her development?

Very important

Somewhat important $\quad 11.3$

No opinion $\quad 3.8$

Not that important $\quad 8.0$

Not at all important

$12 \cdot 8$

Do you feel that a child's diet affects his/her school success later in life?

Very important

Somewhat important

No opinion

Not that important

Not at all important
$52 \cdot 3$

$7 \cdot 5$

$6 \cdot 2$

$10 \cdot 8$

$23 \cdot 2$

\section{Hygiene}

Why is it important to wash hands?

Prevents germs from getting into $\quad 70.0$

Prevents germs from getting into

6-8 months

Mean (SD)

9-11 months

Mean (SD)

12-23 months

Mean (SD)

Did [NAME] eat the following meals?

(score)

6-8 months

Breakfast

Dinner $\quad 51.1$

Snacks $\quad 46 \cdot 7$

9-11 months

Breakfast

Lunch

73.1

Dinner

$84 \cdot 0$

Snacks

$84 \cdot 0$

12-23 months

Breakfast

$77 \cdot 3$

Lunch

$72 \cdot 5$

81.7

Dinner $\quad 83.2$

Snacks $\quad 67.2$
$1,7 \quad 1,6$

$3,1 \quad 1,3$

, 91,5

the food

How do you frequently wash your hands?

Using only water $\quad 8.6$

Using water and $\quad 91.4$ 
Table 3 Continued

\begin{tabular}{|c|c|c|c|c|c|}
\hline Knowledge & $\begin{array}{l}\% \text { of mothers } \\
(n 547)\end{array}$ & Attitude & $\begin{array}{l}\% \text { of mothers } \\
(n 547)\end{array}$ & Practice & $\begin{array}{c}\% \text { of mothers } \\
(n 547)\end{array}$ \\
\hline To stay healthy & 21.0 & & & & \\
\hline Personal hygiene & $15 \cdot 4$ & & & & \\
\hline Prevent child from getting diar- & $29 \cdot 3$ & & & & \\
\hline
\end{tabular}

$\begin{array}{lr}\begin{array}{l}\text { Yesterday, when did you wash } \\ \text { your hands with soap? } \\ \text { Before cooking the }\end{array} & 32.7 \\ \quad \text { meals } & \\ \text { Before eating } & 52.5 \\ \text { After being in toilet } & 73.7 \\ \text { After changing a } & 40.8 \\ \quad \text { child } & \end{array}$

Yesterday, how many times did you wash the hands of [NAME]? (times)

How do you frequently wash the hands of your children?

Using only water $\quad 11.5$

Using water and $\quad 71.9$

soap

Do not wash $\quad 16.5$

'These answer options were abstracted from the original answer option 'other, clarify'.

†The dietary diversity score was calculated by dividing the consumed foods into the seven food groups defined for children and summing the food groups wherefrom a child had eaten during the previous $24 \mathrm{~h}^{(42)}$.

meat. The majority gave various reasons for why continued breast-feeding is important. Regarding the effects of diet, $75.3 \%$ found it important for child development and $69.8 \%$ found diet important for a child's success in life (Table 3).

The index scores on breast-feeding attitudes did not differ significantly $(P=0 \cdot 13)$. However, the attitude towards complementary feeding differed significantly between the three groups according to video viewing frequencies $(P=0.03)$. After adjusting for MCHC, tribe and both mother's and child's age, the differences were no longer significant but showed a trend $(P=0.08)$ (Table 4).

\section{Infant and young child-feeding \& bygiene practices}

The mothers reported very good breast-feeding practices; all children had been breastfed, $97 \%$ had been given colostrum and $79.4 \%$ were still breast-feeding at 12-23 months. Initiation of breast-feeding had not been quite as good: about half of the babies had been put to the breast within the first hour and $9.5 \%$ had been given pre-lacteal feeds (Table 3 ).

The mean meal frequency was $3 \cdot 2$, with about half of the children aged 6-8 months having received food at any given meal, over $80 \%$ of those aged 9-23 months receiving food at lunch and/or dinner and about $70 \%$ getting breakfast and/or snacks. The mean DDS was $2 \cdot 5$, distributed as follows: 1.7 for the 6 - to 8 -month-olds, $3 \cdot 1$ for the 9- to 11 month-olds and 2.9 for the 12- to 23-month-olds (Table 3).
Hygiene practices during the previous day revealed that although most of the mothers washed hands with soap, only a third washed their hands before cooking and less than half after changing a diaper. Children's hands were washed with soap in just over $70 \%$ of the families and $16.5 \%$ did not wash the hands of children at all (Table 3 ).

No statistically significant differences existed in the scores of the breast-feeding practice index nor in complementary feeding practices, that is, DDS and meal frequency, according to video viewing frequencies. In the combined hygiene knowledge and practice index, those who had seen the videos once or twice had a mean score of 31.4, which was significantly lower than those who had seen videos more often ( $P$-values varied). These differences remained significant after adjustment with MCHC, tribe and child's age (Table 4).

\section{Confounding factors}

The most prevalent confounding factors were MCHC and tribe, though child's and mother's age and the number of children impacted some indexes and indicators (Table 4). The most video viewings were reported in MCHC 1-3 (Supplementary Table 2), all located in Nairobi, indicating shorter distances to the MCHC and thereby easier access to see videos. Tribes varied with geographical location. While $40.5 \%$ of mothers with children aged 12-23 months saw videos five or more times, only $23.5 \%$ of those with 
C- Table 4 Indexes constructed from questions presented in Table 3 and associated scores; meal frequency and dietary diversity score (DDS) as indicators of complementary feeding practices

\begin{tabular}{|c|c|c|c|c|c|c|c|c|c|c|c|}
\hline \multirow{3}{*}{$\begin{array}{l}\text { Has watched } \\
\text { study videos }\end{array}$} & \multirow[b]{3}{*}{$n$} & \multicolumn{3}{|c|}{ Knowledge } & \multicolumn{3}{|c|}{ Knowledge } & \multirow[b]{3}{*}{$P$-value* } & \multicolumn{2}{|c|}{ Knowledge \& Practice } & \\
\hline & & \multicolumn{3}{|c|}{ Breast-feeding } & \multicolumn{3}{|c|}{ Complementary feeding } & & \multicolumn{3}{|c|}{ Hygiene } \\
\hline & & Mean & $95 \% \mathrm{CL}$ & $P$-value* & & Mean & $95 \% \mathrm{CL}$ & & Mean & $95 \% \mathrm{CL}$ & $P$-value* \\
\hline $\begin{array}{l}1-2 \text { times } \\
3-4 \text { times } \\
5 \text { or more times }\end{array}$ & $\begin{array}{l}199 \\
154 \\
194\end{array}$ & $\begin{array}{l}21 \cdot 8^{\mathrm{a}} \\
24 \cdot 0 \\
25 \cdot 5^{\mathrm{a}}\end{array}$ & $\begin{array}{l}20 \cdot 4,23 \cdot 2 \\
22 \cdot 4,25 \cdot 6 \\
24 \cdot 1,26 \cdot 9\end{array}$ & $\begin{array}{r}0.001 \\
a=0.001\end{array}$ & & $\begin{array}{l}26 \cdot 1^{a, b} \\
31 \cdot 4^{a} \\
29 \cdot 6^{b}\end{array}$ & $\begin{array}{l}24 \cdot 3,28 \cdot 0 \\
29 \cdot 3,33 \cdot 5 \\
27 \cdot 8,31 \cdot 5\end{array}$ & $\begin{aligned} & 0.001 \\
a & =0.001 \\
b & =0.02\end{aligned}$ & $\begin{array}{l}31 \cdot 4^{a \cdot b} \\
35 \cdot 9^{a} \\
37 \cdot 5^{b}\end{array}$ & $\begin{array}{l}29 \cdot 6,33 \cdot 2 \\
33 \cdot 9,37 \cdot 9 \\
35 \cdot 7,39 \cdot 3\end{array}$ & $\begin{array}{l}<0.0001 \\
a=0.003 \\
b<0.0001\end{array}$ \\
\hline Adjusted means & & $\begin{array}{c}\text { Adjusted } \\
\text { meant }\end{array}$ & $95 \%$ CL & $P$-value $\neq$ & & $\begin{array}{l}\text { Adjusted } \\
\text { mean§ }\end{array}$ & $95 \% \mathrm{CL}$ & $P$-value $\ddagger$ & $\begin{array}{c}\text { Adjusted } \\
\text { meanll }\end{array}$ & $95 \%$ CL & $P$-value $\neq$ \\
\hline $\begin{array}{l}1-2 \text { times } \\
3-4 \text { times } \\
5 \text { or more times }\end{array}$ & $\begin{array}{l}199 \\
154 \\
194\end{array}$ & $\begin{array}{l}22 \cdot 7 \\
24 \cdot 4 \\
25 \cdot 1\end{array}$ & $\begin{array}{l}21 \cdot 0,24 \cdot 5 \\
22 \cdot 5,26 \cdot 3 \\
24 \cdot 1,26 \cdot 9\end{array}$ & 0.06 & & $\begin{array}{l}28 \cdot 3^{\mathrm{a}} \\
32 \cdot 7^{\mathrm{a}} \\
30 \cdot 7\end{array}$ & $\begin{array}{l}29 \cdot 7,34 \cdot 2 \\
30 \cdot 6,35 \cdot 2 \\
28 \cdot 3,33 \cdot 1\end{array}$ & $a=0.01$ & $\begin{array}{l}33 \cdot 6^{a \cdot b} \\
37 \cdot 3^{a} \\
37 \cdot 5^{b}\end{array}$ & $\begin{array}{l}31 \cdot 4,35 \cdot 7 \\
34 \cdot 9,39 \cdot 6 \\
35 \cdot 3,39 \cdot 7\end{array}$ & $\begin{aligned} & 0.003 \\
a & =0.02 \\
b & =0.01\end{aligned}$ \\
\hline \multirow[b]{3}{*}{$\begin{array}{l}\text { Has watched } \\
\text { study videos }\end{array}$} & \multicolumn{4}{|c|}{ Attitude } & \multicolumn{4}{|c|}{ Attitude } & & & \\
\hline & \multicolumn{4}{|c|}{ Breast-feeding } & \multicolumn{4}{|c|}{ Complementary feeding } & & & \\
\hline & $n$ & Mean & $95 \%$ CL & $P$-value* & & Mean & $95 \% \mathrm{CL}$ & $P$-value* & & & \\
\hline $\begin{array}{l}1-2 \text { times } \\
3-4 \text { times } \\
5 \text { or more times }\end{array}$ & $\begin{array}{l}199 \\
154 \\
194\end{array}$ & $\begin{array}{l}54 \cdot 0 \\
55 \cdot 8 \\
57 \cdot 2\end{array}$ & $\begin{array}{l}51 \cdot 7,56 \cdot 3 \\
53 \cdot 2,58 \cdot 3 \\
55 \cdot 0,59 \cdot 6\end{array}$ & $0 \cdot 13$ & & $\begin{array}{l}52 \cdot 6^{a \cdot b} \\
56 \cdot 4^{a} \\
56 \cdot 3^{b}\end{array}$ & $\begin{array}{l}50 \cdot 4,54 \cdot 8 \\
53 \cdot 9,58 \cdot 9 \\
54 \cdot 1,58 \cdot 5\end{array}$ & $\begin{aligned} & 0.03 \\
a= & 0.06 \\
b= & 0.053\end{aligned}$ & & & \\
\hline Adjusted means & & $\begin{array}{l}\text { Adjusted } \\
\text { meanๆ }\end{array}$ & $95 \% \mathrm{CL}$ & $P$-value $\ddagger$ & & $\begin{array}{l}\text { Adjusted } \\
\text { mean }^{\star *}\end{array}$ & $95 \%$ CL & $P$-value $\ddagger$ & & & \\
\hline \multirow[t]{3}{*}{$\begin{array}{l}1-2 \text { times } \\
3-4 \text { times } \\
5 \text { or more times }\end{array}$} & $\begin{array}{l}199 \\
154 \\
194\end{array}$ & $\begin{array}{l}54 \cdot 4 \\
55 \cdot 7 \\
57 \cdot 1\end{array}$ & $\begin{array}{l}52 \cdot 1,56 \cdot 7 \\
53 \cdot 2,58 \cdot 3 \\
54 \cdot 8,59 \cdot 4\end{array}$ & 0.23 & & $\begin{array}{l}54 \cdot 5 \\
58 \cdot 2 \\
57\end{array}$ & $\begin{array}{l}51 \cdot 6,57 \cdot 3 \\
55 \cdot 1,61 \cdot 2 \\
54 \cdot 1,60 \cdot 0\end{array}$ & 0.08 & & & \\
\hline & & \multicolumn{3}{|c|}{ Practice } & \multicolumn{4}{|c|}{ Practice } & \multicolumn{3}{|c|}{ Practice } \\
\hline & & \multicolumn{3}{|c|}{ Breast-feeding } & \multicolumn{4}{|c|}{$\begin{array}{l}\text { Complementary feeding - Meal } \\
\text { frequency }^{\mathrm{a}}\end{array}$} & \multicolumn{3}{|c|}{ Complementary feeding - DDS } \\
\hline $\begin{array}{l}\text { Has watched } \\
\text { study videos }\end{array}$ & $n$ & Mean & $95 \% \mathrm{CL}$ & $P$-value* & $n$ & Mean & $95 \% \mathrm{CL}$ & $P$-value* & Mean & $95 \% \mathrm{CL}$ & $P$-value* \\
\hline $\begin{array}{l}1-2 \text { times } \\
3-4 \text { times } \\
5 \text { or more times }\end{array}$ & $\begin{array}{l}199 \\
154 \\
194\end{array}$ & $\begin{array}{l}86 \cdot 6 \\
88 \cdot 2 \\
87\end{array}$ & $\begin{array}{l}84 \cdot 6,88 \cdot 7 \\
85 \cdot 9,90 \cdot 5 \\
85 \cdot 0,89 \cdot 1\end{array}$ & 0.60 & $\begin{array}{l}126 \\
103 \\
156\end{array}$ & $\begin{array}{l}3 \cdot 2 \\
3 \cdot 2 \\
3 \cdot 2\end{array}$ & $\begin{array}{l}2 \cdot 8,3.5 \\
2 \cdot 8,3 \cdot 6 \\
2.9,3.5\end{array}$ & 0.98 & $\begin{array}{l}2.5 \\
2.5 \\
2.6\end{array}$ & $\begin{array}{l}2 \cdot 2,2 \cdot 8 \\
2 \cdot 2,2 \cdot 8 \\
2 \cdot 3,2 \cdot 8\end{array}$ & 0.82 \\
\hline Adjusted means & & $\begin{array}{l}\text { Adjusted } \\
\text { meant† }\end{array}$ & $95 \% \mathrm{CL}$ & $P$-value $\neq$ & $n$ & $\begin{array}{l}\text { Adjusted } \\
\text { meanł‡ }\end{array}$ & $95 \%$ CL & $P$-value $\neq$ & $\begin{array}{c}\text { Adjusted } \\
\text { meanף }\end{array}$ & $95 \%$ CL & $P$-value $\neq$ \\
\hline $\begin{array}{l}1-2 \text { times } \\
3-4 \text { times } \\
5 \text { or more times }\end{array}$ & $\begin{array}{l}199 \\
154 \\
194\end{array}$ & $\begin{array}{l}86 \cdot 7 \\
88 \cdot 4 \\
86 \cdot 8\end{array}$ & $\begin{array}{l}84 \cdot 7,88 \cdot 7 \\
86 \cdot 0,90 \cdot 7 \\
84 \cdot 8,88 \cdot 9\end{array}$ & 0.51 & $\begin{array}{l}126 \\
103 \\
156\end{array}$ & $\begin{array}{l}3 \cdot 3 \\
3 \cdot 3 \\
3 \cdot 1\end{array}$ & $\begin{array}{l}3 \cdot 0,3 \cdot 7 \\
2 \cdot 9,3 \cdot 6 \\
2 \cdot 8,3 \cdot 3\end{array}$ & 0.36 & $\begin{array}{l}2 \cdot 6 \\
2.5 \\
2.5\end{array}$ & $\begin{array}{l}2 \cdot 3,2 \cdot 9 \\
2 \cdot 2,2 \cdot 9 \\
2 \cdot 3,2 \cdot 7\end{array}$ & 0.84 \\
\hline
\end{tabular}

Post hoc pairwise comparisons: Tukey's test.

Differences in pairwise comparisons market with superscript letters.

${ }^{2}$ The meal frequency was calculated as the sum of meals eaten by a child during the previous $24 \mathrm{~h}$.

${ }^{*}$ ANOVA or Kruskal-Wallis.

†Adjusted for MCHC, tribe and mother's age.

†ANOVA.

$\S$ Adjusted for MCHC, tribe and number of children in household

IIAdjusted for MCHC, tribe and child's age.

TAdjusted for MCHC.

${ }^{\star \star}$ Adjusted for MCHC, tribe, child's age and mother's age.

††Adjusted for number of children in household.

$\ddagger \ddagger$ Adjusted for MCHC and child's age. 
hildren aged 0-6 months saw videos as often (Supplementary Table 2). Information on breast-feeding might not have been as new and interesting as information on complementary feeding, as evident from the knowledge indexes, thus engaging mothers with older babies.

\section{Discussion}

Overall, the reception of the videos was very positive. The participants in the FGD reported that they learned many important things about IYCF from the videos. This finding was supported by the KAP results, as the index scores of breast-feeding and complementary feeding knowledge and hygiene were associated with the frequency of video viewing.

Several mothers participating in the FGD reported that learning had become easier with the videos. They could now see in action what they had previously only heard described, making the information easier to process and remember. Modelling behaviour, as imitated by the videos, has proven effective in IYCF education ${ }^{(28)}$. For example, cooking demonstrations can improve the quality of complementary foods ${ }^{(29)}$.

The mothers in our study found health talks and the opportunity to ask questions important for their learning. The videos alone may not be enough to deepen maternal learning but may need coupling with health talks and discussions during which someone explains the content. The same was found in Uganda, where positive results on video education concerned situations where parents were offered the opportunity to ask questions during each video viewing $^{(15)}$. In Nairobi slums, the lack of both social and professional support has been recorded as an explanation for babies not being exclusively breastfed ${ }^{(30)}$. The mere importance of health talks as a social learning environment could be essential to changing attitudes, whereby the health care workers could offer support to the mothers, and the mothers to each other ${ }^{(11)}$. The videos also offered a way of standardising the messages provided during the health talks. Such standardisation could support maternal learning, as consistent messages are important in helping mothers feel confident in making IYCF decisions ${ }^{(31)}$.

The challenges reported during the FGD were language, irrelevant videos for mothers' specific situations and disruptions. Studies have shown that learning is more effective if teaching is done in the first language of the student ${ }^{(32)}$. Second, it is important for a mother to receive IYCF education specific to her situation.

Our main result from the intervention was that the more videos were watched, the better was the complementary feeding knowledge and hygiene knowledge and practices, as was breast-feeding knowledge though it weakened slightly after adjustments. Also elsewhere IYCF counselling has been documented as effective only when continuous ${ }^{(33,34)}$. The WHO and UNICEF recommend that all mothers receive at least six breast-feeding counselling sessions ${ }^{(35)}$ and repeated complementary feeding counselling for the first 2 years ${ }^{(36)}$. It was evident from the FGD that the mothers had not seen all videos, with a seeming overrepresentation on the videos at the beginning of the set. This would have impacted the KAP results, as it cannot be expected that mothers could have correctly answered questions related to videos they had not seen. It is also likely that mothers who had seen the videos more often had also seen a wider variety of videos.

As a lack of knowledge and adverse advice or beliefs are the most influential barriers to correct $\mathrm{IYCF}^{(1)}$, discovering that the videos could influence not only knowledge on complementary feeding but also showed a trend in attitudes was encouraging. Also in Mexico, educational IYCF interventions improved beliefs about nutrient-dense foods, such as green vegetables, meat and fish ${ }^{(37)}$. However, no change was seen in attitudes towards breast-feeding. Changing maternal attitudes towards practices like early skin-to-skin contact likely require that these practices are first accepted by healthcare workers and integrated into normal delivery procedures. While early skin-to-skin contact has not been accounted for in Kenyan Demographic Health Surveys ${ }^{(38)}$ or the KAP survey $^{(24)}$ used as a base for the questionnaire of this study, reports from Gambia ${ }^{(39)}$ and Nigeria ${ }^{(40)}$ show low rates of early skin-to-skin contact.

Even though the hygiene knowledge and practice index was related to video viewings, the same was not seen in breast-feeding practices and indicators of complementary feeding practices, i.e. DDS and meal frequency. The reported breast-feeding practices left little room for improvement. Breast-feeding education must be implemented early in pregnancy, before mothers have made breast-feeding decisions $^{(41)}$, or perhaps even earlier if breast-feeding and child-feeding practices are learnt during childhood or teenage years ${ }^{(5)}$. The mean DDS among the children in our study (2.5) is nearly half of the recommended minimal DDS of $4^{(42)}$, and many children were not fed any meals, especially in the youngest age group, showing that both the DDS and meal frequency were insufficient to meet children's dietary needs. Although the results from the FGD suggested that a few mothers had learned to re-allocate their food budgets to better follow what they were learning from the videos, poverty remains a major barrier for proper complementary feeding in Africa $^{(1,43)}$, with a third of Kenyans living in food poverty $^{(44)}$. However, complementary feeding education has been shown to improve child growth parameters, even in food insecure areas ${ }^{(45)}$, indicating that efforts should be continued. Moreover, our intervention only lasted 6 months; more time may be needed to change IYCF practices on scale.

The implications of the study were seen not only as better knowledge but also in reported changes in behaviour, even if they might have only seen a few videos. The deepened knowledge had helped some mothers change old beliefs rooted in the society and enabled them to act against those beliefs. Similarly, education through specific IYCF 
messages helped transform feeding practices in Zimbabwe ${ }^{(46)}$, despite cultural beliefs that are contrary to feeding recommendations. The education through videos also empowered mothers with a deeper trust in their own knowledge, which in turn allowed them to follow recommendations even when facing adversity. This empowerment enabled them to spread the messages of the videos to their friends and family. As Nguyen et al. ${ }^{(47)}$ conclude, IYCF messages can diffuse to the community through social networks and thus promote lasting positive changes in IYCF practices. Additionally, the videos acted as a motivator for mothers to attend their appointments at MCHC and some came to clinic just to see the videos.

The strength of the study is that we applied both qualitative and quantitative methods to better understand the acceptance and influence of ICYF educational videos. The FGD provided us with rich data indicating saturation. Including different study areas likely gave us a good estimate of how viewing frequencies affect KAP within diverse settings and mothers. The study was conducted in a real-life situation, mimicking what would happen if the programme was applied to existing MCHC routines.

There are also some limitations. Some of the FGD were conducted in local languages and translated into English, allowing for meaning to be lost in translation and the data were analysed by researchers from a different culture, making it possible that some nuances were missed. However, the moderators who translated the transcripts were nutritionists fluent in English and familiar with the subject. As for all interview studies, interviewer strategies in this study may have varied, though they were trained to minimise this. As the mothers were asked how many times they had seen the videos, this, as well as the DDS variable, are subject to memory bias. However, the intervention period was not very long, making it less likely to forget visits to the MCHC. Additionally, there were breaks in video showing in two MCHC which were addressed as quickly as possible.

\section{Conclusions}

Our results show that video education is an approved method of providing culturally appropriate IYCF education in Africa. The empowerment gained through learning from videos can help mothers deepen their own understanding and spread correct IYCF practices. The videos seem beneficial when they are watched repeatedly, and the learning process is supported by healthcare workers. Therefore, our conclusion is that the videos could supplement current IYCF education efforts in Kenya and integrating video education on scale should be encouraged. They should be used to strengthen health talks and not replace these. However, further studies are needed to establish the effects of video education compared with traditional education. In addition, these should determine ways of offering mothers both more target-specific education according to their current needs and opportunities to learn according to their own terms and schedules. Another relevant topic for study is educating other family members such as fathers and grandmothers.

\section{Acknowledgements}

Acknowledgements: The authors are most grateful to the data collection team and the mothers who participated in the interviews, without whom, the study would not have been possible. We also wish to thank the Academy of Finland for funding the study. Financial support: This study as funded by the Academy of Finland (Grant no. 287967). Conflict of interest: The authors declare that they have no conflicts of interest. Authorship: L.S., M.M., S.O. and K.U. designed the study. J.K. and C.L. supervised the data collection. L.S. transcribed the FGD data and L.S., K.U. and S.O. analysed it. K.U. cleaned the KAP data and M.K. analysed it. L.S. and M.M. interpreted the data and are primarily responsible for the final content. L.S. wrote the manuscript, and M.M. and S.O. reviewed and contributed to it. All authors have read and approved the final manuscript. Ethics of buman subject participation: This study was conducted according to the guidelines laid down in the Declaration of Helsinki, and all procedures involving research participants were approved by the AMREF Health Africa Ethics and Scientific Review committee in Nairobi (ESRC P111/ 2014). Written or verbal informed consent was obtained from all subjects/patients. Verbal consent was witnessed and formally recorded. All participants remain anonymous; mothers, healthcare workers and mother-child pairs were given a numerical code for data processing.

\section{Supplementary material}

For supplementary material accompanying this paper visit https://doi.org/10.1017/S1368980021002342

\section{References}

1. Nankumbi J \& Muliira J (2015) Barriers to infant and childfeeding practices: a qualitative study of primary caregivers in Rural Uganda. J Health Popul Nutr 33, 106-116.

2. Waswa LM, Jordan I, Herrmann J et al. (2015) Communitybased educational intervention improved the diversity of complementary diets in western Kenya: results from a randomized controlled trial. Public Health Nutr 18, 3406-3419.

3. Hadley C, Tessema F, Lema TB et al. (2010) What knowledge and expectations are Ethiopian girls bringing with them into parenthood? Food Nutr Bull 31, 495-502.

4. Bandura A (1977) Social Learning Theory. Englewood Cliffs, NJ: Prentice-Hall Inc. 
5. Hadley C, Patil C \& Gulas C (2010) Social learning and infant and young child feeding practices. Curr Anthropol 51, 551-560.

6. Paul KH, Muti M, Khalfan SS et al. (2011) Beyond food insecurity: how context can improve complementary feeding interventions. Food Nutr Bull 32, 244-253.

7. Kakute PN, Ngum J, Mitchell P et al. (2005) Cultural barriers to exclusive breastfeeding by mothers in a rural area of Cameroon, Africa. J Midwifery Womens Health 50, 324-328.

8. Sirota D \& Hametz P (2013) A pilot study to establish better eating practices using an exam room-based educational video. ICAN 5, 370-374.

9. Tuong W, Larsen E \& Armstrong A (2014) Videos to influence: a systematic review of effectiveness of video-based education in modifying health behaviors. J Behav Med 37, 218-233.

10. Bezemer J (2017) Visual research in clinical education. Med Educ 51, 105-113.

11. Horii N, Habi O, Dangana A et al. (2016) Community-based behavior change promoting child health care: a response to socio-economic disparity. J Health Popul Nutr 35, 12.

12. Scheinmann R, Chiasson MA, Hartel D et al. (2010) Evaluating a bilingual video to improve infant feeding knowledge and behavior among immigrant Latina mothers. $J$ Community Health 35, 464-470.

13. Adhisivam B, Vishnu Bhat B, Poorna R et al. (2017) Postnatal counseling on exclusive breastfeeding using video - experience from a tertiary care teaching hospital, South India. J Matern Fetal Neonatal Med 30, 834-838.

14. Arinitwe R, Willson A, Batenhorst S et al. (2020) Using a Global Health Media Project video to increase knowledge and confidence in the mothers of admitted neonates in Rwanda: a prospective interventional study. J Trop Pediatr 66, 136-143.

15. Mutanda JN, Waiswa P \& Namutamba S (2016) Communitymade mobile videos as a mechanism for maternal, newborn and child health education in rural Uganda; a qualitative evaluation. Afr Health Sci 16, 923-928.

16. Desta BF, Mohammed H, Barry D et al. (2014) Use of mobile video show for community behavior change on maternal and newborn health in rural Ethiopia. J Midwifery Womens Health 59, S65-S72.

17. Kenya National Bureau of Statistics (2017) Economic Survey 2017. https://www.knbs.or.ke/download/economic-survey2017/ (accessed February 2018).

18. Shadish WR, Cook TD \& Campbell DT (2002) Experimental and Quasi-Experimental Designs for Generalized Causal Inference. Houghton: Mifflin and Company.

19. World Health Organization (2009) Infant and young child feeding: Model Chapter. https://www.who.int/nutrition/ publications/infantfeeding/9789241597494/en/ (accessed February 2014).

20. UNICEF (2012) Community IYCF Counselling Package. Key messages booklet. https://www.unicef.org/nutrition/files/ Key_Message_Booklet_2012_small.pdf (accessed February 2014).

21. Pan American Health Organization/World Health Organization (2003) Guiding principles for complementary feeding of the breastfed child. https://www.who.int/maternal_child_ adolescent/documents/a85622/en/ (accessed February 2014).

22. World Health Organization Fact sheets (last updated 2021). https://www.who.int/news-room/fact-sheets (accessed April 2014).

23. Ramsay SA, Holyoke L, Branen LJ et al. (2012) Six characteristics of nutrition education videos that support learning and motivation to learn. J Nutr Educ Behav 44, 614-617.

24. Ministry of Health (MOH) Kenya (2014) Maternal, Infant and Young Child Nutrition Program KAPs Questionnaire. Available upon request from the Ministry of Health.
25. Krippendorff K (1980) Content Analysis: An Introduction to Its Methodology. Newbury Park: Sage Publications.

26. Graneheim UH \& Lundman B (2004) Qualitative content analysis in nursing research: consepts, procedures and measures to achieve trustworthiness. Nurse Educ Today 24, 105-112.

27. SAS Institute Inc (2013) Cary, NC, USA: SAS Institute Inc. Available at: https://www.sas.com/en_us/software/all-products.html (accessed August 2014)

28. Briscoe C \& Aboud F (2012) Behaviour change communication targeting four health behaviours in developing countries: a review of change techniques. Soc Sci Med 75, 612-621.

29. Majamanda J, Maureen D, Munkhondia TM et al. (2014) The effectiveness of community-based nutrition education on the nutrition status of under-five children in developing countries. A systematic review. Malawi Med J 26, 115-118.

30. Kimani-Murage EW, Wekesah F, Wanjohi M et al. (2015) Factors affecting actualisation of the WHO breastfeeding recommendations in urban poor settings in Kenya. Maternal Child Nutr 11, 314-332.

31. Våga BB, Moland KM, Evjen-Olsen B et al. (2014) Reflections on informed choice in resource-poor settings: the case of infant feeding counselling in PMTCT programmes in Tanzania. Soc Sci Med 105, 22-29.

32. UNESCO (2008) Mother Tongue Matters: Local Language as a Key to Effective Learning. Paris: UNESCO.

33. Ochola SA, Labadarios D \& Nduati RW (2013) Impact of counselling on exclusive breast-feeding practices in a poor urban setting in Kenya: a randomized controlled trial. Public Health Nutr 16, 1732-1740.

34. Kim SS, Rawat R, Mwangi EM et al. (2016) Exposure to large-scale social and behavior change communication interventions is associated with improvements in infant and young child feeding practices in Ethiopia. PLoS One 11, e0164800.

35. World Health Organization (2018) Guideline: counselling of women to improve breastfeeding practices. https://apps.who. int/iris/bitstream/handle/10665/280133/9789241550468-eng. pdf (accessed January 2021).

36. UNICEF (2020) Improving Young Children's Diets During the Complementary Feeding Period. https://www.unicef.org/ nutrition/files/Complementary_Feeding_Guidance_2020_ portrait_ltr_web2.pdf (accessed January 2021).

37. Monterrosa EC, Frongillo EA, González de Cossío T et al. (2013) Scripted messages delivered by nurses and radio changed beliefs, attitudes, intentions, and behaviors regarding infant and young child feeding in Mexico. J Nutr 143, 915-922.

38. Kenya National Bureau of Statistics, Ministry of Health/ Kenya, National AIDS Control Council/Kenya et al. (2015) Kenya Demographic and Health Survey 2014. Rockville, MD: Kenya National Bureau of Statistics, Ministry of Health/Kenya, National AIDS Control Council/Kenya, Kenya Medical Research Institute, National Council for Population and Development/Kenya, and ICF International.

39. Ekholuenetale M, Onikan A \& Ekholuenetale CE (2020) Prevalence and determinants of mother and newborn skinto-skin contact in The Gambia: a secondary data analysis. J Egypt Public Health Assoc 95, 18.

40. Singh K, Khan SM, Carvajal-Aguirre L et al. (2017) The importance of skin-to-skin contact for early initiation of breastfeeding in Nigeria and Bangladesh. J Global Health 7, 020505 .

41. Kellams AL, Gurka KK, Hornsby PP et al. (2018) A randomized trial of prenatal video education to improve breastfeeding among low-income women. Breastfeed Med 13, 666-673.

42. World Health Organization (2010) Indicators for assessing infant and young child feeding practices, part 2 , measurement. 
https://www.who.int/maternal_child_adolescent/documents/ 9789241599290/en/ (accessed February 2021).

43. Victor R, Baines SK, Agho KE et al. (2014) Factors associated with inappropriate complementary feeding practices among children aged 6-23 months in Tanzania. Matern Child Nutr 10, 545-561.

44. Korir L, Rizov M \& Ruto E (2020) Food security in Kenya: insights from a household food demand model. Econ Modelling 92, 99-108.

45. Bhutta ZA, Das JK, Rizvi A et al. (2013) Evidence-based interventions for improvement of maternal and child nutrition: what can be done and at what cost? Lancet $\mathbf{3 8 2}$ 452-477.

46. Paul KH, Muti M, Chasekwa B et al. (2012) Complementary feeding messages that target cultural barriers enhance both the use of lipid-based nutrient supplements and underlying feeding practices to improve infant diets in rural Zimbabwe. Matern Child Nutr 8, 225-238.

47. Nguyen PH, Frongillo EA, Kim SS et al. (2019) Information diffusion and social norms are associated with infant and young child feeding practices in Bangladesh. J Nutr 149, $2034-2045$. 